\title{
INOVAÇÃO, ESTRATÉGIA, ORIENTAÇÃO PARA O MERCADO E EMPREENDEDORISMO: IDENTIFICAÇÃO DE CLUSTERS DE EMPRESAS E TESTE DE MODELO DE PREDIÇÃO DO DESEMPENHO NOS NEGÓCIOS
}

\section{Cid Gonçalves Filho}

Doutor em Administração pela Universidade Federal de Minas Gerais - UFMG

Coordenador do Programa de Doutorado e Mestrado em Administração da Fundação Municipal para Educação Comunitária - FUMEC

cid@ fumec.br (Brasil)

\section{Mara Regina Veit}

Mestre em Administração pela da Fundação Municipal para Educação Comunitária - FUMEC mara.veit@ sebraemg.com.br (Brasil)

\section{Plínio Rafael Reis Monteiro}

Doutor em Administração pela Universidade Federal de Minas Gerais - UFMG

Coordenador do Programa de Doutorado e Mestrado em Administração da Fundação Municipal para Educação Comunitária - FUMEC

plínio.monteiro@fumec.br (Brasil)

\section{RESUMO}

Este estudo buscou identificar agrupamentos (clusters) de micro e pequenas empresas, por critérios de inovação e desempenho, bem como desenvolver um modelo hipotético de antecedentes da inovação em micro e pequenas empresas no país. A premissa fundamental é que fatores internos a empresa, tal como a orientação ao mercado, o grau de inovação e o perfil dos empreendedores conjuntamente com fatores exógenos a empresa são determinantes de seu desempenho organizacional e do grau de inovação implementado. Conjugando questionamentos e alternativas teóricas para o relacionamento entre estes construtos, foi proposto e estado um modelo estrutural de antecedentes da inovação (Hair $e t$ al., 1998). Para tanto foi conduzido um survey nacional que contou com uma amostra de 1.552 empresários ligados a base SEBRAE. Os resultados demonstram que o perfil empreendedor pode agir como o determinante da orientação ao mercado adotada pelas empresas e seu grau de inovação. Tais fatores por consequência poderiam ser considerados determinantes do desempenho organizacional. O trabalho classifica as empresas em agrupamentos, por níveis de desempenho e inovação, e demonstra as diferenças entre os quatro perfis de organizações encontrados. Nos grupos identificados, de alto e baixo nível de inovação, se observaram diferenças significativas no perfil do empreendedor, bem como em seu nível de orientação ao mercado, sugerindo um papel relevante da orientação ao mercado para o desempenho de empresas inovadoras. $\mathrm{O}$ trabalho contribui de forma significativa para compreensão do problema e dos antecedentes da inovação em organizações no cenário brasileiro.

Palavras-chave: Inovação; Orientação para mercado; Empreendedorismo; Comportamento empreendedor. 


\section{INTRODUÇÃO}

A sociedade moderna é uma fonte promulgadora do espírito empreendedor: seja pela necessidade de trabalho, pela falta de alternativas de emprego ou por um instituto nato de ser gestor de seu próprio destino. Há evidências de que a dinâmica do cenário econômico mundial impele, cada vez mais, os indivíduos a buscarem, por seus próprios recursos, os meios de trabalho capazes de garantirem suas sobrevivências e alimentarem seus anseios de realização profissional e pessoal (Drucker, 2003).

Deste modo, o indivíduo com maior potencial a empreender se destaca em meio à multidão devido ao seu espírito inovador, perseverança e afinco na busca de suas metas. Este tipo de indivíduo que impulsiona a economia, provendo novos bens de consumo e inovadores métodos de produção e ofertas ao mercado (Schumpeter, 1982; Timmons, 1989).

Não obstante, os desafios enfrentados pelos empreendedores por vezes perpassam seu potencial: fatores exógenos, tal como o contexto estratégico geral e a turbulência ambiental, são capazes de minar os sonhos e culminam por enclausurar idéias e esforços quem, em outros contextos, poderiam se revelar promissores à sociedade.

Neste cenário, convergem duas linhas de estudos dentro do contexto da estratégia empresarial. Em primeira instância, levanta-se a importância do perfil individual para a obtenção de bons resultados financeiros e mercadológicos, revelando-se que parte considerável do sucesso dos negócios se deve à características de personalidade e estilos de vida dos empreendedores (McClelland, 1961). Nesta linha, o estudo do perfil do empreendedor, da relação deste com a definição da estratégia empresarial (Mintzberg, 2001) e seu impacto sobre o desempenho nos negócios, se revela como ramo profícuo e que desperta interesse por entes privados, públicos e pela sociedade como um todo.

Por outro lado, um grupo de estudos tradicionais busca integrar fatores ambientais e a estratégia adotada pelo negócio. O intuito é avaliar como tais elementos contribuem para o desempenho empresarial. Nesta linha, aborda-se como orientação para o mercado se reflete sobre o desempenho dos negócios. Outra vertente procura identificar como fatores exógenos a empresa, tais como o ambiente reativo e agressivo do setor (turbulência ambiental) apresenta um reflexo sobre os resultados observados pelas empresas.

Conjugando-se as visões precedentes, chega-se um ponto de confluência entre campos teóricos relacionados, mas ainda pouco explorados de maneira conjunta. Afinal, qual seria a relação existente 
entre o perfil empreendedor, a orientação para o mercado, fatores ambientais? Qual seria o efeito conjunto destes fatores sobre o desempenho nos negócios?

Alinhado com tais questionamentos este estudo buscou identificar qual seria a relação entre o perfil do empreendedor, a orientação para o mercado, a turbulência ambiental e o desempenho nos negócios. Após uma breve introdução sobre os termos prementes nestes ramos dos estudos da estratégia, será apresentada a metodologia concebida neste estudo, bem como será avaliada a qualidade de dois modelos teóricos rivais testados. Ao fim do estudo, conclusões gerenciais e teóricas serão tecidas, conjuntamente com a discussão acerca das limitações e cautelas que a presente abordagem revela ao leitor.

\section{REVISÃO DA LITERATURA}

\subsection{Perfil do empreendedor}

São inúmeros estudos que buscaram identificar o perfil empreendedor e se procurou, por meio de autores clássicos e pesquisas empíricas realizadas no meio cientifico e empresarial, fazer um resumo sobre o tema. Em 1961, McClelland iniciou seus estudos sobre o tema do empreendedorismo, que foram ampliados em 1982, por meio de um survey com empreendedores de 32 países, e corroborados por muitas pesquisas e experimentos posteriores.

Foi utilizado um teste de avaliação motivacional - o TAT - Thematic Aperception Test e testes de resolução de problemas, cujos resultados demonstraram que o indivíduo empreendedor possui uma estrutura motivacional diferenciada pela presença marcante de uma necessidade específica: a necessidade de realização. Para o pesquisador, a motivação pela realização conjugada com as dez características do comportamento empreendedor - CCE's - são os fatores essenciais para o crescimento econômico dos indivíduos e contribuem para explicar a aparente indiferença de muitos e a sensibilidade de poucos para oportunidades econômicas que se apresentam no ambiente. (McClelland, 1961).

O economista Schumpeter (1982) foi um dos primeiros pensadores, que no início do século $\mathrm{XX}$, procurou traduzir o sentido do empreendedorismo, quando descreveu a contribuição dos empreendedores na formação de riqueza como o processo de destruição criativa. $\mathrm{O}$ autor afirma que a essência do empreendedorismo está na percepção e na exploração de novas oportunidades, no âmbito

Revista de Administração e Inovação, São Paulo, v. 10, n.2, p.81-101, abr./jun. 2013. 
dos negócios, utilizando recursos de maneira inovadora. Para o autor, sem inovação não há empreendedores; sem investimentos, não há retorno de capital e o capitalismo não se propulsiona. A partir dessa análise, os economistas passaram a ver os empreendedores como detectores de oportunidades de negócios, criadores de empresas e corredores de risco.

Carland, Carland e Hoy (1992) desenvolveram um instrumento para medir o potencial empreendedor de um indivíduo, medido pelo CEI - Carland Entrepreneurship Index, que vem sendo aprimorado e aplicado em outros grupos de pesquisa. Os autores concluíram que o empreendedorismo é uma integração de cinco elementos: necessidade de realização, criatividade, propensão à inovação, ao risco e à postura estratégica, relacionada pelos autores como a busca de oportunidade.

Segundo Carland, Carland e Hoy (1992) a maior ou menor presença destas características em um indivíduo definem o seu potencial segundo a escala CEI, que pontua os respondentes com valores de zero a 33 pontos, contidos em três faixas|: microempreendedor, empreendedor e macroempreendedor. O CEI é um questionário de autorresposta com trinta e três frases combinadas e afirmativas em pares, no formato de escolha forçada e seu objetivo principal é identificar o potencial empreendedor dos empreendedores dos respondentes.

Carland (1996) e sua equipe de pesquisadores identificaram nos resultados das pesquisas três características maiores da personalidade empreendedora como: a propensão a assumir riscos, a preferência pela inovação e pela criatividade e a necessidade de realização. Esses três fatores integrados, identificados na pesquisa CEI - Carland Entrepreneurship Index, compõem o perfil do empreendedor por ele percebido e sua compreensão tem fundamentado a construção de pesquisas sobre o potencial empreendedor (Carland, 1996).

A pesquisa GEM - Global Entrepreneurship Monitor, aplicada em 35 países, desde o ano de 2000, procura identificar a TEA - Taxa de Empreendedorismo, nos países participantes, considerando os motivos que levam os empreendedores a empreenderem seja por necessidade ou oportunidade. São aplicados 54 critérios na pesquisa que também busca avaliar as condições de competitividade entre os países, os fatores que contribuem para a atividade empreendedora e as políticas públicas que estimulam a atividade empresarial. O Brasil, que também participa da pesquisa, tem ocupado as seguintes posições em relação aos demais países: 2006 - 5; $2005-7^{\circ} ; 2004-7^{\circ} ; 2003-6^{\circ} ; 2002-$ $7^{\circ} ; 2004-8^{\circ}$ (GEM/SEBRAE, 2001 a 2006).

Evidências passadas demonstram que existe uma relação considerável entre o perfil empreendedor e o desempenho nos negócios. No trabalho de Veit, Gonçalves-Filho e Gonçalves (2007), chegou-se a estimativa de que aproximadamente $25 \%$ da variância do desempenho das 
empresas e do negócio podem ser explicados pelo empreendedor. Não obstante como alguns autores sugerem (Oliveira, 2007 e Mintzberg, 2001), o perfil empreendedor pode ser considerado um fator que leva os gestores e definirem estratégias de negócios mais ajustadas. Neste sentido, podem-se sugerir as hipóteses de que existe uma relação positiva entre o perfil empreendedor e o desempenho ou que esta relação é mediada pela orientação para o mercado. Tais concepções serão definidas na apresentação e teste dos modelos rivais de pesquisa.

\subsection{Estratégia e Desempenho Organizacional: a influência da Orientação ao Mercado, Turbulência Ambiental e Inovação}

O conceito de marketing foi introduzido por volta do início dos anos 50 e sua fundamentação filosófica promove a ideia de que as organizações devem se orientar para as necessidades de seus clientes a fim de obterem maior desempenho (Jaworski e Kohli, 1993). Desde então, a tem se tornado popular pesquisas que visam verificar a extensão com que as empresas têm aplicado os conceitos de marketing, bem como as consequências e os antecedentes desta postura organizacional (Jaworski e Kohli, 1993).

Neste sentido, pode-se apontar que empresas que desejam gerar valor superior para seus clientes e obter vantagens competitivas sustentáveis, deve-se ter um negócio capaz de ter uma cultura geradora de comportamentos orientados ao mercado. Nesse sentido, definem orientação para o mercado como sendo uma cultura organizacional que objetiva criar, de forma eficiente e efetiva, comportamentos que gerem valor representativo para os clientes e, consequentemente, maiores resultados no mercado. Assim, uma empresa orientada para o mercado seria aquela que sempre está avaliando alternativas capazes de gerar vantagens competitivas sustentáveis, optando por aquelas capazes de gerar maior valor presente e futuro para o público-alvo.

Conforme salientam Narver e Slater (1990), a orientação para o mercado é resultado de três posturas: orientação para o cliente, orientação para os competidores e coordenação interfuncional. A premissa desta abordagem é que, para que uma empresa se oriente a seus clientes e concorrentes, seria que o fluxo de informações dos ambientes interno e externo transitassem com fluidez. Portanto, gerir o conhecimento de clientes e concorrentes tornam-se modalidades fundamentais para propiciar o crescimento do conhecimento de marketing, fomentando uma adequada e eficaz orientação ao mercado. Em síntese, a orientação ao mercado segundo a proposição de Narver e Slater (1990) pode ser vislumbrada na FIG. 1:

Revista de Administração e Inovação, São Paulo, v. 10, n.2, p.81-101, abr./jun. 2013. 


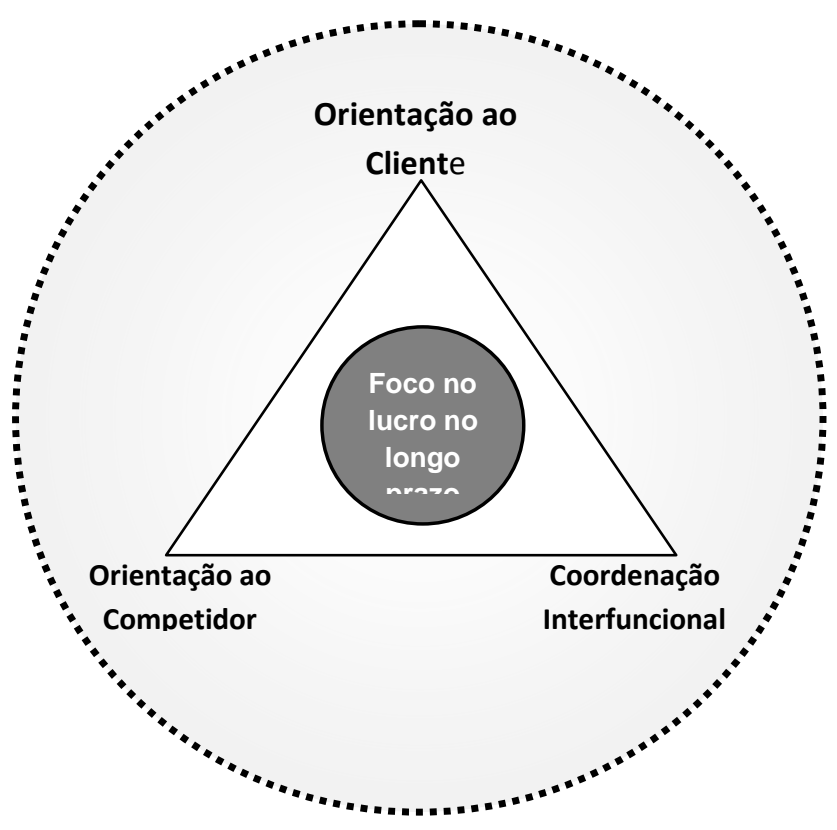

Figura 1 - Orientação ao mercado

Fonte: Narver e Slater, 1990.

Usando a conceituação dos autores supracitados, pode-se definir a orientação ao cliente como o grau em que a organização busca compreender seu mercado-alvo no intuito de oferecer valor superior para seus clientes. Por orientação ao concorrente, entende-se o grau de compreensão de forças e fraquezas da concorrência e da própria empresa, bem como o entendimento das capacidades e estratégias de longo prazo dos demais players em um mercado. Por fim, a coordenação interfuncional se direciona a utilização organizada de recursos organizacionais com intuito de prover aos clientes produtos e serviços de maior valor agregado e prover estratégias efetivas diante das interposições da concorrência.

Evidências demonstram que a orientação para o mercado enquanto um esforço interdepartamental direcionado ao longo prazo geram resultados superiores em termos (Jaworski e Kohli, 1993). No entanto, não somente os fatores internos influenciam o desempenho organizacional. Segundo Jaworski e Kohli (1993) a orientação caminha lado a lado com fatores como a turbulência ambiental e intensidade da concorrência. Conforme propuseram os autores, tais elementos podem por vezes suplantar a estratégia que fora determinada internamente na organização minando os efeitos positivos que poderiam emergir de uma atuação direcionada ao mercado.

Outro elemento fundamental neste contexto seria a capacidade da organização gerenciar o conhecimento produzido em direção a inovações em seus produtos, serviços e processos. Tal como 
sugerem Han, Kim e Srivastava (1998) não seria possível falar em orientação ao mercado e desempenho sem considerar o efeito da inovação neste contex to (inovatividade).

\section{MÉTODO}

Este estudo caracteriza-se como de natureza conclusiva descritiva que fora, aplicado por meio de um survey eletrônico autopreenchido, do tipo vertical (Churchill e Iacobucci, 2003). Os dados foram coletados a partir de uma amostra autogerada obtida a partir de mailing do SEBRAE contendo empreendedores cadastrados na instituição. A população de interesse foram empreendedores atuais que atuam em todo território nacional. $\mathrm{O}$ instrumento de pesquisa fora elaborado a partir da adaptação da escala desenvolvida por Veit, Gonçalves-Filho e Gonçalves (2007) e depuradas por Oliveira (2007). A lista dos itens, inicialmente adicionados à escala, pode ser visto no quadro 1:

\section{Quadro 1- Construtos indicadores e fontes do estudo}

\begin{tabular}{|c|c|}
\hline $\begin{array}{l}\text { INDICADORES E } \\
\text { CONSTRUTOS }\end{array}$ & PERGUNTAS \\
\hline \multirow{5}{*}{ RISCO } & Tenho capacidade para lidar com incertezas e riscos. \\
\hline & Para ser melhor que os outros nos negócios, preciso assumir alguns riscos. \\
\hline & Para crescer profissionalmente preciso assumir alguns riscos. \\
\hline & $\begin{array}{l}\text { Tomo algumas decisões sem ter informações que me garantam qual o melhor } \\
\text { caminho a seguir. }\end{array}$ \\
\hline & Aceito naturalmente os riscos em minha vida profissional. \\
\hline \multirow{6}{*}{$\begin{array}{l}\text { PLANEJAMENTO } \\
\text { FORMAL }\end{array}$} & $\begin{array}{l}\text { Estabeleço regras e padrões para minhas atividades cotidianas } \mathrm{e} \\
\text { profissionais. }\end{array}$ \\
\hline & Uma das coisas mais importantes para o sucesso é o planejamento. \\
\hline & Descrever metas e objetivos é crucial para o sucesso. \\
\hline & Um plano deve ser escrito para ser efetivo. \\
\hline & $\begin{array}{l}\text { Procedimentos operacionais bem definidos são fundamentais para se fazer } \\
\text { um bom trabalho. }\end{array}$ \\
\hline & É importante estabelecer regras e processos para se ter sucesso nos negócios. \\
\hline \multirow{5}{*}{$\begin{array}{l}\text { PENSAMENTO } \\
\text { ANALÍTICO }\end{array}$} & Gosto de abordar as situações a partir de uma perspectiva analítica. \\
\hline & Sou uma pessoa que gosta de pensar logicamente. \\
\hline & $\begin{array}{l}\text { Quando tenho um problema analiso detalhadamente a situação antes de } \\
\text { tomar uma decisão. }\end{array}$ \\
\hline & $\begin{array}{l}\text { Decisões devem ser tomadas rapidamente para serem efetivas e darem } \\
\text { resultados. }\end{array}$ \\
\hline & Penso que é importante ser lógico. \\
\hline
\end{tabular}

Revista de Administração e Inovação, São Paulo, v. 10, n.2, p.81-101, abr./jun. 2013. 
Inovação, estratégia, orientação para o mercado e empreendedorismo: identificação de clusters de empresas e teste de modelo de predição do desempenho nos negócios

\begin{tabular}{|c|c|}
\hline \multirow{7}{*}{ INOVAÇÃO } & $\begin{array}{l}\text { Busco novas soluções e inovações para atender as necessidades das pessoas } \\
\text { para quem trabalho. }\end{array}$ \\
\hline & Penso que sou uma pessoa imaginativa. \\
\hline & Aprecio o desafio de inventar mais do que qualquer coisa. \\
\hline & Gosto de pensar que sou uma pessoa criativa. \\
\hline & Prefiro trabalhar com pessoas criativas. \\
\hline & Sempre procuro formas diferentes para fazer meu trabalho cotidiano. \\
\hline & $\begin{array}{l}\text { No dia a dia procuro reinventar tarefas e rotinas do trabalho, mudando } \\
\text { processos. }\end{array}$ \\
\hline \multirow{5}{*}{ RELACIONAMENTO } & Tenho um bom relacionamento com meus colegas de trabalho. \\
\hline & As pessoas pensam em mim como alguém fácil de relacionar. \\
\hline & Preocupo-me com os sentimentos das pessoas que trabalham comigo. \\
\hline & Meus colegas de trabalho são como minha segunda família. \\
\hline & Considero-me amigo das pessoas que trabalham comigo. \\
\hline \multirow{8}{*}{ DESAFIO } & $\begin{array}{l}\text { Trabalho incansavelmente na busca de realização dos meus sonhos } \\
\text { profissionais }\end{array}$ \\
\hline & Não descansarei até alcançar meus sonhos profissionais. \\
\hline & O desafio de ter sucesso é tão importante quanto ganhar dinheiro. \\
\hline & Adoro a ideia de competir e superar os outros. \\
\hline & Aprecio solucionar problemas no meu dia a dia profissional. \\
\hline & Encaro o trabalho como um desafio que gosto de superar diariamente. \\
\hline & Ficaria frustrado caso meu trabalho deixasse de me oferecer desafios. \\
\hline & Gosto da ideia de superar problemas e dificuldades diariamente. \\
\hline \multirow{8}{*}{ DEDICAÇÃO } & O sucesso profissional é minha principal prioridade na vida. \\
\hline & Uma das coisas mais importantes na minha vida é ter sucesso profissional. \\
\hline & Meus objetivos pessoais giram em torno do sucesso profissional. \\
\hline & $\begin{array}{l}\text { Pelo sucesso profissional abriria mão de algum tempo com minha família e } \\
\text { amigos. }\end{array}$ \\
\hline & $\begin{array}{l}\text { As pessoas com que convivo quase sempre me aconselham a me dedicar } \\
\text { menos ao trabalho e profissão para ter algum tempo disponível para os } \\
\text { amigos e família. }\end{array}$ \\
\hline & Estou disposto a trabalhar muito pelo meu sucesso profissional. \\
\hline & $\begin{array}{l}\text { Muitas vezes trabalho em dias e horários de descanso/folga em meu projeto } \\
\text { de negócio. }\end{array}$ \\
\hline & Minha vida gira em torno da minha profissão. \\
\hline \multirow{8}{*}{ COMPETÊNCIA } & Ajo de forma pró-ativa ao ser pressionado pelas circunstâncias ou ameaças. \\
\hline & Utilizo a rede de contatos pessoais para atingir meus objetivos profissionais. \\
\hline & $\begin{array}{l}\text { Tenho responsabilidade na conclusão dos trabalhos dentro das metas e prazos } \\
\text { estipulados. }\end{array}$ \\
\hline & Confio na minha competência para empreender como fonte do sucesso. \\
\hline & $\begin{array}{l}\text { Assumo a responsabilidade pela resolução de problemas que possam } \\
\text { prejudicar meu sucesso. }\end{array}$ \\
\hline & Gosto de atuar em equipe nas tarefas para cumprir prazos. \\
\hline & $\begin{array}{l}\text { Confio na minha capacidade de enfrentar e superar os desafios e os } \\
\text { obstáculos. }\end{array}$ \\
\hline & $\begin{array}{l}\text { Mantenho meus objetivos com foco mesmo diante de resultados inicialmente } \\
\text { insatisfatórios. }\end{array}$ \\
\hline
\end{tabular}

Revista de Administração e Inovação, São Paulo, v. 10, n.2, p.81-101, abr./jun. 2013. 
Fonte: Dados da pesquisa.

Além destas questões, havia no instrumento de pesquisa perguntas sobre o perfil do respondente e questões sobre Orientação ao Mercado de Narver e Slater (1990), sua Turbulência Ambiental (Jaworski e Kohli, 1993) e seu grau de inovatividade.

Foram usadas medidas subjetivas de desempenho contemplando medidas de participação de mercado, lucratividade, aumento da receita com vendas, retorno sobre os ativos, desempenho geral e capacidade de inovação, em conformidade com os trabalhos de Slater e Narver (1990) e Kohli e Jaworski (1990). Tal escolha se deve à evidências de que não existem diferenças significativas entre medidas objetivas ou subjetivas de desempenho (Perin e Sampaio, 1999), a necessidade de se contemplar diferentes indústrias e segmentos (Slater e Narver, 1994) e buscando facilitar a obtenção de respostas.

\section{ANÁLISE DOS DADOS}

A análise de dados foi dividida em quatro blocos adotando-se os softwares SPSS $13.0^{\circledR}$, e AMOS 5.0 ${ }^{\circledR}$ e Microsoft Excel ${ }^{\circledR}$.

\subsection{Descrição do Perfil da amostra}

Inicialmente foram excluídos casos repetidos (indivíduos que responderam mais de uma vez) e respondentes com respostas excessivamente repetidas (60 casos que usaram a mesma nota para mais 80\% do questionário, dois desvios padrão acima da média) obteve-se uma amostra final de 1552 empreendedores atuais sejam eles formais ou informais (empresários com negócio informal - sem CNPJ). Destes $86 \%$ detinham negócios no estado de Minas Gerais. O principal motivo salientado para abertura do negócio fora a oportunidade percebida na atividade e o crescimento no mercado.

A amostra apresentou o seguinte perfil: A maior parte dos respondentes tem empresa na forma societária (45\%), sendo ainda 26\% empresas familiares (com esposa/marido) e somente $27 \%$ firmas individual (2\% são empresas de terceiros). Dentre as empresas com sócios 66\% tem dois sócios, 9\% um sócio e $95 \%$ tem seis sócios ou menos. Quanto à natureza do negócio 27\% eram comércios, 53\% eram de serviços, $4 \%$ indústria e $1 \%$ agropecuária (7\% eram outras atividades). Quanto ao recurso 
inicial aplicado no negócio, a maior parte investiu menos de R \$ 5.000,00 (29,6\%) e 16\% investiram mais de $\mathrm{R} \$ 50.000,00$. O tempo médio de existência das empresas foi de 6,5 anos (desvio=7,79; mínimo=0,02; máximo=87), sendo que $78 \%$ têm menos de 10 anos de existência e $34 \%$ menos de 2 anos.

Quanto às características demográficas, 64\% dos empreendedores eram do sexo masculino; a idade em média foi de 36 anos (desvio=10,01; mínimo=18; máximo=86), a maior parte têm curso superior incompleto (22\%) ou completo (27\%); 62\% são casados e $29 \%$ são solteiros. Quanto à renda e; $66 \%$ têm renda familiar mensal inferior a $\mathrm{R} \$ 5.000$.

\subsection{Análises Preliminares}

Como não existiam dados ausentes na base de dados (survey eletrônico com resposta obrigatória) analisou-se a normalidade dos dados onde se mostrou que as não se comportam conforme a distribuição normal. No entanto, considerando o tamanho expressivo da amostra pode-se dizer que os procedimentos inferência de máxima verossimilhança, apesar de não dispensarem completamente a normalidade, produzem resultados mais consistentes que alternativas disponíveis como WLS, PLS e ADF.

Quanto aos outliers foram encontradas 2.597 respostas extremas uni variadas, pelo critério do intervalo interquartil, dispersas em 826 casos representando 2,3\% da base de dados. Tais valores foram substituídos por valores menos ofensivos conforme sugere Kline (1998) Ainda assim permaneceram 215 casos extremos multivariados que foram mantidos para verificar seu efeito sobre estimativas gerais de ajuste do modelo.

Quando analisada a linearidade, por meio dos diagramas de dispersão, e a multicollinearidade (valores VIF [variance inflation factor - fator de inflação da variância] menores que 10) não foram detectados problemas na base de dados. Em sequência, partiu-se a avaliação à dimensionalidade das escalas de Orientação para o mercado, Inovatividade e turbulência ambiental. A escala de Potencial do Perfil Empreendedor - PPE, foi analisada em detalhes em um estudo anterior (Veit et al., 2009) de validação do instrumento.

Aplicou-se a Análise Fatorial Exploratória - AFE com extração de fatores por eixos principais (objetivo de encontrar as dimensões latentes a escala) e usando o critério de análise do scree plot. Para a escala de orientação para o mercado encontrou-se uma solução com três dimensões e com ajuste adequado (valor $\mathrm{KMO}=0,929 ; 64 \%$ da variância explicada). Para as escalas de inovatividade e 
turbulência ambiental encontrou-se dois fatores distintos (valor $\mathrm{KMO}=0,748 ; 61 \%$ da variância explicada) demonstrando a estabilidade da escala.

A confiabilidade das escalas, avaliadas por meio do Alpha de Cronbach, ficaram acima dos limites sugeridos de 0,70 (Malhotra, 2001). A validade convergente foi acessada pela avaliação das significâncias das cargas fatoriais padronizadas na Análise Fatorial Confirmatória - AFC, conforme sugerem Bagozzi et al., (1991). Usando a estimação de máxima verossimilhança (para evitar erros de não normalidade multivariada) todos os indicadores dos constructos tiveram cargas fatoriais significativas em seus respectivos construtos o modelo de mensuração.

Para avaliar a validade discriminante, comparou-se a variância média extraída dos indicadores com o quadrado do coeficiente de correlação entre os constructos latentes na AFC, conforme sugerem Fornell e Lacker (1981). Usando esse procedimento, a validade discriminante só não foi obtida para os constructos valor no consumo e qualidade. Usando o teste de diferença qui-quadrado sugerido por Bagozzi et al., (1991) obteve-se evidências de validade discriminante entre os construtos valor no consumo e qualidade $\left(\square_{\text {dif }}^{2}=7,318\right.$ ), indicando que ambos podem ser considerados como construtos diferentes, mas relacionados. Um resumo das etapas de validação pode ser visto na Tabela 1.

Tabela 1 - Matriz de correlações, percentual de variância extraída, correlações ao quadrado e indicadores de qualidade dos constructos

\begin{tabular}{|c|c|c|c|c|c|c|c|c|c|c|c|c|c|c|}
\hline & $\mathrm{CE}$ & $\mathrm{R}$ & $\mathrm{PA}$ & $\mathrm{DE}$ & DS & $\mathrm{PF}$ & I & REL & DES & IN & CINT & $\mathrm{CI}$ & OCON & OCL \\
\hline $\mathrm{CE}$ & 0,44 & 0,09 & 0,29 & 0,12 & 0,38 & 0,13 & 0,18 & 0,17 & 0,17 & 0,22 & 0,03 & 0,28 & 0,32 & 0,41 \\
\hline $\mathrm{R}$ & 0,30 & 0,39 & 0,07 & 0,05 & 0,10 & 0,07 & 0,16 & 0,05 & 0,03 & 0,04 & 0,01 & 0,04 & 0,06 & 0,08 \\
\hline PA & 0,54 & $0,2^{\prime} 7$ & $\mathbf{0 , 4 0}$ & 0,07 & 0,19 & 0,20 & 0,08 & 0,07 & 0,05 & 0,07 & 0,01 & 0,17 & 0,19 & 0,19 \\
\hline $\mathrm{DE}$ & 0,35 & 0,22 & 0,26 & 0,40 & 0,17 & 0,04 & 0,10 & 0,02 & 0,02 & 0,04 & 0,02 & 0,04 & 0,07 & 0,05 \\
\hline DS & 0,61 & 0,32 & 0,44 & 0,41 & $\mathbf{0 , 5 0}$ & 0,09 & 0,25 & 0,12 & 0,08 & 0,13 & 0,02 & 0,18 & 0,20 & 0,22 \\
\hline PF & 0,37 & 0,27 & 0,44 & 0,20 & 0,30 & 0,41 & 0,07 & 0,08 & 0,02 & 0,03 & 0,02 & 0,05 & 0,04 & 0,08 \\
\hline I & 0,43 & 0,39 & 0,28 & 0,32 & 0,50 & 0,27 & $\mathbf{0 , 3 8}$ & 0,11 & 0,04 & 0,14 & 0,03 & 0,12 & 0,16 & 0,18 \\
\hline REL & 0,42 & 0,23 & 0,27 & 0,15 & 0,35 & 0,28 & 0,34 & $\mathbf{0 , 4 2}$ & 0,08 & 0,08 & 0,02 & 0,17 & 0,15 & 0,19 \\
\hline DES & 0,42 & 0,16 & 0,22 & 0,16 & 0,29 & 0,15 & 0,21 & 0,29 & $\mathbf{0 , 5 9}$ & 0,31 & 0,00 & 0,21 & 0,27 & 0,22 \\
\hline IN & 0,46 & 0,21 & 0,27 & 0,19 & 0,36 & 0,19 & 0,37 & 0,28 & 0,56 & $\mathbf{0 , 7 1}$ & 0,00 & 0,38 & 0,38 & 0,36 \\
\hline CINT & 0,17 & 0,10 & 0,12 & 0,14 & 0,14 & 0,15 & 0,17 & 0,15 & $-0,05$ & 0,01 & 0,39 & 0,01 & 0,02 & 0,03 \\
\hline CI & 0,53 & 0,19 & 0,41 & 0,19 & 0,42 & 0,23 & 0,34 & 0,41 & 0,46 & 0,62 & 0,12 & 0,56 & $\underline{0,73}$ & $\underline{0,50}$ \\
\hline OCON & 0,56 & 0,24 & 0,44 & 0,26 & 0,45 & 0,20 & 0,39 & 0,39 & 0,52 & 0,62 & 0,15 & 0,86 & 0,53 & $\underline{0,53}$ \\
\hline OCL & 0,64 & 0,29 & 0,44 & 0,23 & 0,47 & 0,28 & 0,43 & 0,44 & 0,47 & 0,60 & 0,16 & 0,71 & 0,73 & 0,44 \\
\hline $\mathrm{CC}$ & $\mathbf{0 , 8 2}$ & 0,64 & 0,72 & $\mathbf{0 , 8 4}$ & $\mathbf{0 , 8 0}$ & $\mathbf{0 , 7 8}$ & $\mathbf{0 , 7 9}$ & $\mathbf{0 , 7 8}$ & $\mathbf{0 , 9 3}$ & $\mathbf{0 , 8 8}$ & 0,71 & 0,84 & 0,82 & 0,76 \\
\hline AL & $\mathbf{0 , 8 1}$ & 0,72 & $\mathbf{0 , 7 0}$ & 0,79 & 0,75 & $\mathbf{0 , 8 2}$ & $\mathbf{0 , 7 8}$ & 0,77 & $\mathbf{0 , 9 3}$ & $\mathbf{0 , 8 8}$ & 0,73 & $\mathbf{0 , 8 3}$ & 0,81 & 0,74 \\
\hline
\end{tabular}

Fonte: Dados da pesquisa. Observações: os números na diagonal principal correspondem à variância média extraída, segundo procedimentos de Tabachnick e Fidel (2001). Os elementos abaixo da diagonal principal correspondem a correlação estimada na AFC. Os valores da diagonal são o quadrado da correlação entre as variáveis. O valor alfa e a confiabilidade composta (HAIR et al., 1998) são estimativas da confiabilidade dos constructos.

Revista de Administração e Inovação, São Paulo, v. 10, n.2, p.81-101, abr./jun. 2013. 
A Tabela 1 mostra valores elevados de confiabilidade e variância extraída de todos os constructos. Tomando por base a validade discriminante, somente os indicadores do constructo de orientação para o mercado violaram este pressuposto. Testaram-se modelos adicionais que verificaram se uma estrutura fatorial de segunda é mais adequada para os constructos Orientação para o Mercado e Perfil Potencial Empreendedor. Ambos mostraram que uma estrutura de segunda ordem é a melhor representação para estes constructos. Também se conclui que as dimensões de PPE e OM têm validade discriminante, segundo teste de diferença qui-quadrado proposto por Bagozzi et al. (1991). Como considerações acerca da fidegnididade das medidas (Churchill e Iacobucci, 2002), pode-se atestar a confiabilidade e validade das medidas do estudo.

\subsubsection{Teste do Modelo de Pesquisa}

O modelo hipotético de pesquisa foi testado em uma estratégia de modelagem de equações estruturais (HAIR et al., 1998). A amostra final de 1552 respondentes foi inferior ao número de parâmetros na matriz de covariância de entrada que contém 2485 elementos (70x71/2). Não obstante, o número de observações na matriz (2485) e na amostra (1552) são superiores ao número de parâmetros estimados no modelo (161). Isto implica no número de mais de 10 elementos na amostra para cada parâmetro do modelo (o dobro deste valor se analisarmos as variâncias e covariância da matriz de entrada). Reforça-se que isto revela uma amostra razoável para testar o modelo estrutural. O modelo foi ajustado por meio de estimadores de máxima verossimilhança, devido à robustez desse método a desvios da normalidade multivariada quando a amostra é maior que 1.000 casos (Tabachnick e Fidel, 2001). A Figura 2 ilustra os resultados obtidos:

Revista de Administração e Inovação, São Paulo, v. 10, n.2, p.81-101, abr./jun. 2013. 


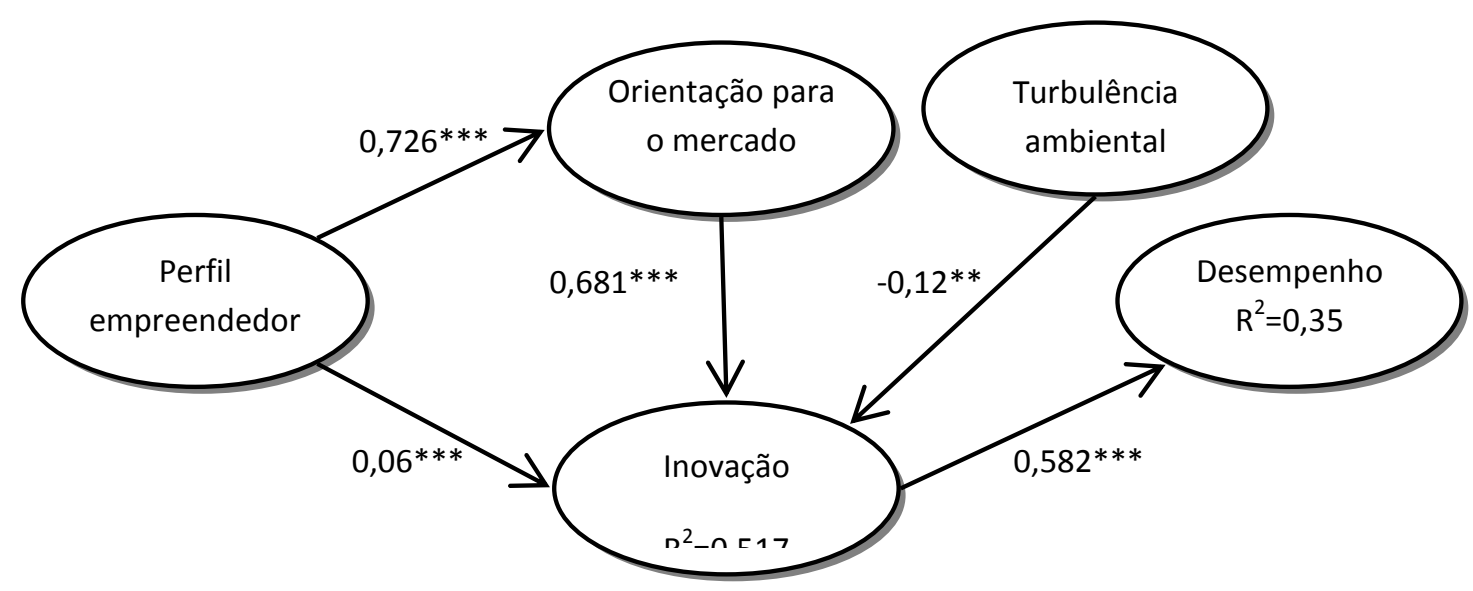

Ajuste do modelo

\begin{tabular}{l|l|l|l}
\hline ÍNDICE & VALOR & ÍNDICE & VALOR \\
\hline$\chi^{2}$ & 8301 & AGFI & 0,847
\end{tabular}

Figura 2 - Modelo Hipotético

Observações: Os valores apresentados junto às setas indicam o valor das cargas padronizadas. ** indica a significância da carga ao nível de $1 \%(\mathrm{p}<0,01)$; *** indica a significância da carga ao nível de $0,1 \%$ ( $\mathrm{p}<0,001)$. O Valor $\mathrm{R}^{2}$ indica o percentual de variância explicada dos construtos endógenos. Indica uma carga não significativa $(\mathrm{P}>0,05)$.

O modelo da Fig. 2 mostra que o modelo da relação entre PPE e desempenho é moderado pela orientação para o mercado e pela capacidade de inovação empresarial. Em outras palavras, em congruência com o que fora encontrado por Oliveira (2007) é possível que o perfil empreendedor não seja a causa direta do desempenho, mas ele é o antecedente de comportamentos organizacionais que levam as empresas a terem um maior desempenho nos negócios. Observa-se que o impacto do PPE é moderado pela orientação ao mercado, conforme sugere Cooper (1984). Tal fato corrobora com os clusters de empresas, classificados e exibidos no item 4.1.4, resultados estes que levam a crer que a inovação orientada ao mercado é um antecedente significativo do desempenho superior .

\subsubsection{Classificação dos Grupos de Empresas por Inovação e Desempenho}

Com o objetivo de identifica e classificar as empresas por níveis de inovação e desempenho, foi executada uma análise de cluster, aplicando a técnica k-means (quick cluster). Foram encontrados quatro grupos, com as seguintes médias dos construtos (Tabela 2):

Revista de Administração e Inovação, São Paulo, v. 10, n.2, p.81-101, abr./jun. 2013. 
Tabela 2 - Grupos de Empresas

\begin{tabular}{|l|c|c|c|c|}
\hline \multirow{2}{*}{ Dimensão } & \multicolumn{4}{|c|}{ Nome do Grupo de Empresas / Cluster } \\
\cline { 2 - 5 } & $\begin{array}{c}\text { A - empresas } \\
\text { que não inovam e } \\
\text { não têm } \\
\text { desempenho }\end{array}$ & $\begin{array}{c}\text { B - Empresas } \\
\text { que inovam e } \\
\text { têm desempenho }\end{array}$ & $\begin{array}{c}\text { C - Empresas que } \\
\text { inovam um pouco } \\
\text { e tem um pouco de } \\
\text { desempenho }\end{array}$ & $\begin{array}{c}\text { D - Empresas } \\
\text { que inovam, } \\
\text { mas não têm } \\
\text { desempenho }\end{array}$ \\
\hline Inovação & 3,39 & $8,78^{\text {acd }}$ & $6,18^{\mathrm{a}}$ & $7,52^{\mathrm{ac}}$ \\
\hline Desempenho & 4,25 & $8,25^{\text {acd }}$ & $6,,^{95 \mathrm{a}}$ & $4,84^{\mathrm{a}}$ \\
\hline $\begin{array}{l}\text { Orientação ao } \\
\text { Mercado }\end{array}$ & 5,31 & $8,31 \mathrm{acd}$ & $7,00 \mathrm{a}$ & $7,07 \mathrm{a}$ \\
\hline Tamanho do Cluster & $176(11,34 \%)$ & $\begin{array}{c}587 \\
(37,82 \% 0\end{array}$ & $\begin{array}{c}488 \\
(31,44 \%)\end{array}$ & 301 \\
$(19,39 \%)$
\end{tabular}

Fonte: dados da pesquisa. Ps: as letras indicam que existe uma diferença significativa entre as médias dos grupos segundo testes $t$ para amostras independentes considerando igualdade das variâncias e um nível de significância de 5\%. As letras ao lado das médias indicam que o grupo em questão tem médias superiores aos grupos, representados pelas letras sobre-escritas.

A análise revela quatro grupos de empresas. O primeiro grupo consiste em empresas que não inovam e não têm desempenho, que representa $11,34 \%$ da amostra. Como o modelo testado demonstra impacto significativo entre inovação e desempenho, tal resultado já era esperado.

O segundo grupo, mais inovador, apresenta desempenho superior, e representa cerca de $37 \%$ da amostra. Já o terceiro grupo é composto de empresas que inovam pouco e possuem desempenho moderado. Por fim há um grupo inovador, mas de baixo desempenho, que representa 19,39\% da amostra.

Em pesquisa empírica realizada por Cooper (1984), o autor identificou cinco grupos (clusters) de empresas, organizados por estratégias. Dentre eles, identificou um grupo de cerca de $26 \%$ de sua amostra (19,4\% nesta pesquisa), de empresas altamente inovadoras e de baixa taxa de crescimento e desempenho, pois as inovações que faziam não eram orientadas ao mercado, ou seja, não possuíam demanda significativa ou geravam valor superior quando comparadas com as ofertas dos concorrentes. Tal achado corrobora com o resultado encontrado neste trabalho.

O grupo que não inova e tem baixo desempenho, conforme a Tabela 2 possui um nível moderado de orientação ao mercado, sendo que o mesmo ocorre com grupo que inova e possui um desempenho inferior. Tal fato sugere a importância da orientação ao mercado para obtenção de desempenho empresarial no ato de inovar, e pode ser observado no modelo hipotético testado. Em outras palavras, inovação só geraria desempenho superior se orientada ao mercado.

Em seguida foi realizada uma análise de diferenças de médias entre características do perfil empreendedor entre os grupos de organizações. O resultado é apresentado na Tabela 3: 
Tabela 3: Diferenças de Médias entre Constructos

\begin{tabular}{|c|c|c|c|c|}
\hline & \multicolumn{4}{|c|}{ Cluster } \\
\cline { 2 - 5 } & $\mathbf{A}$ & $\mathbf{B}$ & $\mathbf{C}$ & $\mathbf{D}$ \\
\hline Competência Estratégica (PPE) & 7,75 & $9,1^{\text {acd }}$ & $8,44^{\mathrm{a}}$ & $8,44^{\mathrm{a}}$ \\
\hline Risco (PPE) & 7,67 & $8,39^{\text {acd }}$ & 7,83 & 7,93 \\
\hline Inovação Empreendedor (PPE) & 6,5 & $7,83^{\text {acd }}$ & $7,02^{\mathrm{a}}$ & $7,41^{\mathrm{ac}}$ \\
\hline Planejamento formal (PPE) & 8,74 & $9,11^{\text {acd }}$ & 8,77 & 8,79 \\
\hline Dedicação (PPE) & 5,79 & $6,82^{\text {ac }}$ & $6,44^{\mathrm{a}}$ & $6,51^{\mathrm{a}}$ \\
\hline Empatia (PPE) & 7,46 & $8,35^{\text {acd }}$ & $7,85^{\text {a }}$ & 7,67 \\
\hline Desafio (PPE) & 7,37 & $8,66^{\text {acd }}$ & $8,06^{\mathrm{a}}$ & $8,05^{\mathrm{a}}$ \\
\hline Pensamento analítico (PPE) & 7,25 & $8,04^{\text {acd }}$ & $7,58^{\mathrm{a}}$ & 7,47 \\
\hline Perfil empreendedor & 7,29 & $8,29^{\text {acd }}$ & $7,74^{\mathrm{a}}$ & $7,79^{\mathrm{a}}$ \\
\hline Média inovação & 3,39 & $8,78^{\text {acd }}$ & $6,18^{\mathrm{a}}$ & $7,52^{\text {ac }}$ \\
\hline Média desempenho & 4,25 & $8,25^{\text {acd }}$ & $6,95^{\text {ad }}$ & $4,84^{\text {a }}$ \\
\hline
\end{tabular}

Fonte: dados da pesquisa. PS: as letras indicam que existe uma diferença significativa entre as médias dos grupos segundo testes $t$ para amostras independentes considerando igualdade das variâncias e um nível de significância de 5\%. As letras ao lado das médias indicam que o grupo em questão tem médias superiores aos grupos representados pelas letras sobre-escritas.

Foram observadas diferenças significativas entre o perfil empreendedor dos grupos empresariais. No grupo B, de empresas inovadoras de alto desempenho, observa-se que os sócios são mais empreendedores (vide média do Perfil Empreendedor - PPE), com nível de 8,29. Já nas empresas do grupo A, pouco inovadoras e de baixo desempenho, verifica-se o nível de PPE mais baixo de todos os grupos (7,29). Por outro lado, nas empresas de desempenho moderado, grupos C e D, verifica-se que o valor do PPE é menor que o Grupo B (alto desempenho e inovador) e maior que do grupo A, que não inova e tem desempenho baixo. Deste modo, em todos os sentidos, sugere-se uma possível relação entre perfil empreendedor e o nível de inovação, de forma possivelmente moderada pela orientação ao mercado.

Observando-se ainda a Tabela 3, cabe ressaltar que existem diferenças entre as dimensões do perfil empreendedor dos grupos. O grupo B tem um perfil mais inovador (dimensão do PPE Inovação do Empreendedor - grau de ...), com diferenças significativas para os demais grupos. Os grupos CD possuem características empreendedoras semelhantes, exceto no perfil mais inovador do empreendedor do grupo D. No que se refere à dimensão planejamento formal do PPE, os grupos ACD possuem médias similares, com diferenças significativas existentes somente para com o grupo B. Em outras palavras, esta característica é de certa forma presente nos empreendedores destes grupos, mas não é capaz por si de explicar diferenças no grau de inovação destas empresas (ou seja, possivelmente há pouca relação entre planejamento formal e inovação).

Revista de Administração e Inovação, São Paulo, v. 10, n.2, p.81-101, abr./jun. 2013. 


\section{DISCUSSÃO E CONCLUSÕES}

No presente estudo, foram observadas evidências que permitissem uma investigação mais completa sobre o relacionamento entre a orientação ao mercado, inovatividade empresarial (capacidade de inovação), turbulência ambiental e o perfil do potencial empreendedor, verificando o impacto destes construtos sobre o desempenho das firmas. Aqui são traçadas as principais conclusões da pesquisa, conjugando-as com os objetivos propostos bem como delimitando as limitações deste estudo.

Inicialmente há de se convir que, de acordo com o exposto no referencial, foi suportado o impacto positivo da orientação para o mercado sobre a inovação e desempenho nas empresas pesquisadas, na perspectiva dos respondentes. $\mathrm{O}$ mesmo ocorre para a inovatividade empresarial e de forma negativa para a turbulência (quanto maior a turbulência menor o grau de inovação). Possivelmente empresas em um ambiente de alta turbulência busquem vencer a competição com enfoque em imitação ou diferenciação incremental e menos inovação de uma forma mais agressiva. No modelo de pesquisa a inovação explicou $35 \%\left(\mathrm{R}^{2}\right)$ de variação do construto desempenho.

O trabalho também objetivou identificar agrupamentos de empresas no que tange ao grau de inovação e desempenho, bem como descrever características destes grupos no que se refere a Perfil empreendedor e orientação a mercado. Quatro grupos de tamanho representativo foram encontrados, com diferenças significativas de médias nos construtos considerados (inovação e desempenho).

Grupos de alto desempenho e alto grau de inovação se revelaram mais empreendedores e orientados ao mercado. O grupo de baixo desempenho e baixa inovação possui perfil pouco empreendedor e baixa orientação ao mercado, o que revela os riscos deste tipo de atuação e perfil empresarial. Por outro lado, há um grupo inovador e de baixo desempenho, caracterizado por níveis mais baixos de orientação ao mercado, e por fim um grupo meio termo, que inova pouco e tem baixo desempenho.

O PPE apresentou um impacto indireto na inovação, mediado pela orientação ao mercado. Isto se coaduna com os trabalhos de Narver e Slater (1995) que defendem que a relação da orientação para o mercado com valores empreendedores fornece o estímulo necessário para ações inovadoras, demonstrando que ambas as variáveis deveriam ser antecedidas pelo Perfil Potencial do Empreendedor. Deste modo este estudo, justifica e fortalece as conclusões de Narver e Slater

\footnotetext{
Revista de Administração e Inovação, São Paulo, v. 10, n.2, p.81-101, abr./jun. 2013.
} 
(1995), que argumentam que somente a orientação para o mercado não é capaz de estimular ações inovadoras: esta deve ser complementada por uma cultura empreendedora.

Neste modelo, o perfil do potencial empreendedor não revelou uma influência significativa ( $=0,06$ ) sobre a inovação. Contudo, cabe ressaltar que a influência do perfil do potencial empreendedor sobre a inovação foi exercida através da orientação para o mercado. Assim, o perfil do potencial empreendedor pode ser visto como um antecedente da orientação para o mercado e inovatividade das empresas.

Sob a ótica gerencial, este trabalho revelou que desenvolver e incentivar o desenvolvimento do perfil empreendedor é uma postura adequada para obtenção de melhores resultados nos negócios. Assim, o governo, instituições de ensino e entidades de classe devem progressivamente incentivar o desenvolvimento do perfil do empreendedor para aumentar os índices de sobrevivência e impulsionar e a economia, especialmente nas pequenas e médias empresas.

Em sintonia com a fundamentação teórica apresentada, os dirigentes empresariais podem aprimorar o seu potencial empreendedor por meio de treinamentos, palestras, seminários e outras atividades educacionais, e, como consequência, imprimir uma cultura mais orientada para o mercado e mais inovadora, o que provavelmente levará a organização a um desempenho superior. Vale ressaltar que os valores que norteiam toda organização originam-se a partir da alta direção.

No que tange as limitações da pesquisa, sugere-se que novas pesquisas considerem amostras probabilísticas e de abrangência nacional de empreendedores a fim de aumentar a possibilidade de generalização dos resultados encontrados.

Em termos gerais, os resultados obtidos confirmam as hipóteses de investigação aqui delineadas e são coerentes com os resultados encontrados na literatura sobre estratégias empresariais, inovação e o perfil do potencial empreendedor.

\section{REFERÊNCIAS}

Bygrave, D.W.; Zacharakis, A. (2004). The Portable MBA in Entrepreneurship. 3.ed., 494 p. New Jersey: Wiley.

Bagozzi, Richard P., YI, Youjae, Lynn W. Philips. (1991). Assessing construct validity in organizational research. v. 36, pp. 421-458. Administrative Science Quaterly.

Carland, J.A.; Carland, J.W. (1996). The Theoritetical Bases and Dimensionality of the Carland Entrepreneurship Index. (pp.1-24). Proceedings of the RISE 96 Conference, University of Jyvaskylâ,

Revista de Administração e Inovação, São Paulo, v. 10, n.2, p.81-101, abr./jun. 2013. 
Finlândia.

Carland, J.A.; Carland, J.W.; Ensley, M. D. (1999). The Search for the Lead Entrepreneur: Identification Through the Measurement of Entrepreneurial Drive and Skills. Babson College All Rights Reserved. Last Updated January.

Carland, J; Carland, J.A; Hoy, F. (1992). An Entrepreneruship Index: an empirical validation. In: Frontiers do Entrepreneurship Research, França. Proccedings. Massachussets: Babson College.

Churchill, G. Iacobucci, D. (2003). Marketing research: Methodological foundations. 8 th edition. Orlando: Harcourt College Publishers.

Cooper, Robert G. (1984). The impact of new product strategies: what distinguishes top performers? v.1, n.2, pp.151-164. Journal of Product Innovation Management.

Dolabela, F. (1999). O Segredo de Luísa. São Paulo: Cultura e Editores Associados.

Dornelas, J. C. A. (2001). Empreendedorismo: transformando ideias em negócios. Rio de Janeiro: Campus.

Drucker, P. F. (2003). Inovação e espírito empreendedor: prática e princípios. 378 p. São Paulo: Pioneira. $378 \mathrm{p}$.

Druker, P. F. (1992). Administrando para o futuro: os anos 90 e a virada do século. São Paulo: Pioneira.

Filion, L. J. (1999). Empreendedorismo: empreendedores e proprietários-gerentes de pequenos negócios. v. 34, n.2, pp.5-28. Revista de Administração, São Paulo.

GEM - Global Entrepernurship Monitor (2003). Executive Report. Maria Minniti; William D. Bygrave; Erkko Autio. Babson College, US and London Business School, UK. Boston, 42 p.

GEM - Global Entrepernurship Monitor (2004). Executive Report. Zoltam J.Acs; Pia Arenius; Michael Hay Maria Minniti; William D. Bygrave; Erkko Autio. Babson College, US and London Business School, UK. Boston, 48 p.

GEM - Global Entrepernurship Monitor (2005). Executive Report. Maria Minnuti; William D. Bygrave; Erkko Autio. Babson College, US and London Business School, UK. Boston, 48 p.

Gil, A.C. (1991). Como elaborar projetos de pesquisa. São Paulo: Atlas.

Goode, W.J.; Hatt, P. K. (1969). Métodos em pesquisa social. 3 ed. São Paulo: Cia Editora Nacional.

Han, J. K.; Kim, N.; Srivastava, R. K. (1998). Market orientation and organizational performance: Is innovation a missing link? Journal of Marketing, v.62, n.4, pp.30-45, oct.

Hair Jr. Joseph F. et all. (1998). Multivariate data Analysis. $5^{\text {th }}$ ed. Upper Saddle River (NJ): Prentice Hall.

Harvard Business Review. (1999). Entrepreneurship. Boston: Harvard Business School Press. 
Houaiss, A. (2003). Dicionário Houaiss de sinônimos e antônimos. 953 p. Rio de Janeiro: Objetiva.

Inácio Jr., E. (2002). Empreendedorismo e liderança criativa: um estudo com os proprietários gerentes de empresas incubadas no estado do Paraná. Dissertação (Mestrado em Administração) Universidade Federal de Maringá, Maringá.

Joreskog, Karl; Sorbom, Dag. (1998). Lisrel 8 user's reference guide. Chicago: SSI.

Kline, R. B. (1998). Principles and practice of structural equation modeling. New York: The Guilford Press.

Kohli, Ajay K.; Jaworski, Bernard J. (1990). Market orientation: the construct, research propositions, and managerial implications. Journal of Marketing, [S. 1.], v. 54, pp. 1-18.

Kohli, Ajay K.; Jaworski, Bernard J.; Kumar, Ajith. (1993). Markor: a measure of market orientation. Journal of Marketing Research, [S.1.], v. 30, n. 4, pp. 467-477.

Kornijezuk, Fernando .B. S. (2004). Características empreendedoras de pequenos empresários de Brasília. 128f. Dissertação (Mestrado em Administração) - Faculdade de Economia, Administração, Contabilidade e Ciência da Informação e Documentação, Universidade de Brasília, Brasília.

Longenecker, J. G.; Moore, C. W.; Petty, J. W. (1997). Administração de pequenas empresas. São Paulo: Makron Books.

Mcclelland, D. (1961). The achieving society. New York: VanNostrand.

Mintzberg, H.; Quinn, J. B. (2001). O processo da estratégia. Porto Alegre: Bookman.

Narver, John C.; Slater, Stanley F. (1990). The effect of a market orientation on business profitability. Journal of Marketing, [S. 1.], v. 54, pp. 20-35.

Netemeyer, R. G. Bearden, W. O. Sharma, S. (2003). Scaling procedures: Issues and Applications. SAGE.

Oliveira, Thiago dos Santos. (2007). A Orientação para o Mercado e o perfil do Potencial empreendedor nas empresas de Softwares e Serviços. Dissertação de Mestrado. Universidade FUMEC: $116 \mathrm{p}$.

Perin, Marcelo G.; Sampaio, Cláudio H. (1999). Performance Empresarial: uma comparação entre indicadores subjetivos e objetivos. In: ENANPAD, 23, 1999, Foz do Iguaçu - Paraná. Anais... Foz do Iguaçu: ANPAD.

Pestana, M. H. Gageiro, J. N. (2000). Análise de Dados para Ciências Sociais - Complementaridade do SPSS. 2. ${ }^{\circ}$ Ed. Lisboa.

Sampaio, Cláudio Hoffmann. (2000). Relação entre orientação para o mercado e performance empresarial em empresas de varejo de vestuário do Brasil. 234 f. Tese (Doutorado em Administração) - PPGA, UFRGS, Porto Alegre.

Schumpeter, J. A. (1982 [1934]). Teoria do Desenvolvimento Econômico. São Paulo: Abril Cultural. 
SEBRAE - Boletim Estatístico de Micro e Pequenas Empresas - Observatório SEBRAE - Brasília: $1^{\circ}$ semestre, 2005.

SEBRAE - GEM - Pesquisa Global Entrepreneurship Monitor - Empreendedorismo no Brasil Relatório Global. Brasília: 2001, 2002, 2003, 2004,2005 e 2006.

SEBRAE. Fatores condicionantes e taxa de mortalidade de empresas no Brasil. Relatório de pesquisa - Brasília, 2004.

Tabachinik, B. G.; Fidell, L. S. (2001). Using Multivariate Statistics. 4 ed. New York: HarperCollins.

Thimmons, Jeffry A. (1989). The Entrepreneurial Mind. Andover, Massachussetts: Brick House Publishing Company, 187 p.

Veit, M. Gonçalves-Filho; C. F., Gonçalves, C. A. (2007). Mensuração do Perfil do Potencial Empreendedor e seu Impacto no Desempenho das Pequenas Empresas. Anais do ENANPAD, 2007. Rio de Janeiro: Anpad.

Veit. M.; Gonçalves-Filho, C. F.; Gonçalves, C A.; Monteiro, P. R. R.; Quiroga, G. S. (2009). Mensuração do Perfil do Potencial Empreendedor: Desenvolvimento de uma Escala no Cenário Brasileiro. Anais do 3Es, 2009. Recife: Anpad. 
INNOVATION, STRATEGY, MARKET ORIENTATION AND

ENTREPRENEURSHIP: IDENTIFICATION OF CLUSTERS OF COMPANIES AND TEST

PERFORMANCE PREDICTION MODEL IN BUSINESS

\begin{abstract}
This study sought to identify groups (clusters) of micro and small businesses, innovation and performance criteria, as well as develop a hypothetical model of a history of innovation in micro and small enterprises in the country. The fundamental premise is that internal company factors, such as market orientation, the degree of innovation and the profile of entrepreneurs in conjunction with exogenous factors the firm are determinants of organizational performance and the degree of innovation implemented. Combining questions and theoretical alternatives for the relationship between these constructs, it was proposed and a structural model of antecedents of innovation (Hair et al., 1998). To this end a national survey was conducted with a sample of 1,552 businessmen linked to the basis of SEBRAE. The results show that the entrepreneurial profile can act as the determinant of market orientation adopted by the companies and their degree of innovation. Such factors as a result .
\end{abstract}

Key words: Innovation; Market Orientation; Entrepreneurship; Entrepreneurial Behavior.

Data do recebimento do artigo: 05/11/2012

Data do aceite de publicação: 20/02/2013

Revista de Administração e Inovação, São Paulo, v. 10, n.2, p.81-101, abr./jun. 2013. 